\title{
Research on the Coupling of Energy Consumption and High- quality Development in the Yellow River Basin
}

\author{
Jinhui Zhao ${ }^{1}$, Lin Tian ${ }^{1, *}$, Yunlong Bai ${ }^{1}$, Jiawei $\mathrm{He}^{1}$, and Puxi $\mathrm{Li}^{2}$ \\ ${ }^{1}$ School of Mechanical and Power Engineering, Zhengzhou University, 450001 Zhengzhou, Henan, China \\ ${ }^{2}$ International College, Zhengzhou University, 450001 Zhengzhou, Henan, China
}

\begin{abstract}
Understanding the energy development ideas of the Yellow River Basin has a very important impact on the high-quality development of the Yellow River Basin. Aiming at the restriction and promotion of energy consumption in the Yellow River Basin to its high-quality development, this article takes the nine provinces of the Yellow River as the research object, builds an evaluation model based on the data of the river basin from 2004 to 2017, and uses the entropy method and elastic coefficient method to study the coupling characteristics of watershed energy consumption for its high-quality development in time and space. The results show that the high-quality development level of the river basin is generally increasing, the consumption level is generally decreasing, and the coupling of energy consumption and high-quality development is optimized year by year. Finally, according to the coupling of energy consumption level and high-quality development level, a development strategy suitable for improvement is proposed.
\end{abstract}

\section{Introduction}

In recent years, my country has issued and implemented a major regional strategy for the development of the Yangtze River Economic Belt, the construction of the Guangdong-Hong Kong-Macao Greater Bay Area, and the coordinated development of Beijing-Tianjin-Hebei, providing a strong impetus for regional development. In order to form a high-quality development model for the Yellow River Basin, at the 2019 Yellow River Basin Ecological Protection and High-Quality Symposium, General Secretary Xi Jinping clearly proposed a major national strategy for the ecological protection and highquality development of the Yellow River Basin, emphasizing the need for ecological protection and highquality development. Synchronous advancement. However, the Yellow River Basin has been lagging economic development, serious environmental pollution, large consumption of resources and other phenomena, and the coordinated development of resources, environment and economy is poor. At present, there are many problems that restrict the high-quality development of the river basin, and the most urgent task is to solve the energy problem. From the perspective of energy resources, the basin is rich in energy resources, rich in resources such as coal, oil, natural gas and nonferrous metals, and is known as China's "energy basin".

However, with the development of society, the problem of insufficient energy factor support capacity has gradually emerged. The comparative advantage of power energy cost has gradually weakened, the restrictions on mineral resource development have increased, labour costs have continued to rise, the support capacity of reserve resources is insufficient, and the constraints on production factors have continued to increase. Relying on resource input and extensive development scale expansion is difficult to sustain. With resource development as the mainstay, extensive industrial development will be restricted by more stringent factors. Therefore, it is necessary to study the coupling of energy and high-quality development, and then adjust the energy utilization of the river basin to promote the high-quality development of the Yellow River Basin.

\section{Research status}

\subsection{The connotation of high-quality development}

Since the reform and opening up, China's economy has developed rapidly, but it has also brought about many problems, such as environmental degradation and uneven regional development. In recent years, China's economic growth has slowed down, and the development centre has been shifted to high-quality development in order to make China's economic development more mature, stable, and harmonious. The report of the 19th National Congress of the Communist Party of China pointed out: "China's economy has shifted from a stage of rapid growth to a stage of high-quality development. As an important part of China's economic development, the Yellow River region is of great significance to analyse the impact of energy consumption in the Yellow River Basin on its high-quality development ${ }^{[1]}$. Jin Pei ${ }^{[2]}$

* Corresponding author: tianruenhai@163.com 
proposed that the essential feature of high-quality development is to meet the growing multi-faceted needs of the people in various effective and sustainable ways. Wan Guanghua ${ }^{[3]}$ proposed that the ultimate goal of high-quality development is the happiness of the people. On the whole, although no clear definition is given, they all put forward a comprehensive concept, that is, the essential feature is "meeting the people's growing needs for a better life", the fundamental requirement is "high quality", and the fundamental path is "available." continued". Understanding these meanings will help build the Yellow River Basin evaluation system for indepth research, and analyse the internal mechanism of energy consumption for the high-quality development of the Yellow River region through the resourceenvironment-economic evaluation index system and the energy consumption level index system. The entry point is to analyse the coupling between energy consumption and high-quality development.

\subsection{Current status of research on the impact of energy on high-quality development}

Through research on the relationship between energy consumption and the economy, scholars at home and abroad have come to the following two relationships: Kraft ${ }^{[4]}$ and Soytas ${ }^{[5]}$ and Zhao Jinwen ${ }^{[6]}$ believe that energy consumption has a one-way causal relationship to the economy; Zhang Zirong ${ }^{[7]}$. $\mathrm{Xu} \mathrm{Yi}{ }^{[8]}$ believes that there is a relationship between energy consumption and economy that promotes and restricts each other. In general, energy consumption is inseparable from economic development. Although extensive energy consumption can promote economic development, it hinders the improvement of high-quality development. Therefore, a correct analysis of the impact of energy consumption on resource-environmental-economic development is of great significance to the high-quality development of the Yellow River Basin. In recent years, my country has begun to gradually promote the energy revolution in order to seek high-quality development. He Jishan ${ }^{[9]}$ proposed to promote the energy revolution to help the transformation and upgrading of the entire industry while meeting the energy security needs of economic development, and to promote high-quality development in the region. Zhang Xin ${ }^{[10]}$ proposed that the energy transition is the driving force for high-quality development.

Comprehensive research on high-quality development and energy consumption shows that highquality development mainly lies in the aspects of economy, resources, environment, etc., while the influencing factors of energy consumption include energy consumption and structure. This article will analyse the relationship between high-quality development and energy consumption from the three aspects of environmental factors, economic factors, and resource factors for high-quality development in the Yellow River Basin, and the structure and consumption of energy consumption. Based on the coupling relationship of the Yellow River Basin, we are looking for ways to control energy consumption in the Yellow River Basin to promote the high-quality development of the Yellow River Basin.

\section{Research methods}

\subsection{Entropy Method}

Entropy weight method has been widely used in engineering technology, social economy and other fields. It can use the statistical properties of selected indicators to determine weights, avoiding subjective arbitrary weighting of indicators, so this method is adopted for energy consumption. It is measured with the level of high-quality development, and the specific calculation steps are detailed in reference ${ }^{[11]}$.

\subsubsection{Evaluation system}

Table 1. Resource-Environment-Economy Level Index System.

\begin{tabular}{|c|c|c|c|}
\hline Target layer & $\begin{array}{l}\text { Criterion } \\
\text { layer }\end{array}$ & Element layer & $\begin{array}{l}\text { Indicator } \\
\text { attributes }\end{array}$ \\
\hline \multirow{13}{*}{$\begin{array}{l}\text { High-quality } \\
\text { development } \\
\text { level }\end{array}$} & \multirow{8}{*}{ Resources } & $\begin{array}{l}\text { Cultivated land } \\
\text { area per capita }\end{array}$ & Positive \\
\hline & & $\begin{array}{l}\text { Water resources } \\
\text { per capita }\end{array}$ & Positive \\
\hline & & Forest cover rate & Positive \\
\hline & & Power generation & Positive \\
\hline & & $\begin{array}{l}\text { Percentage of total } \\
\text { industrial water } \\
\text { consumption }\end{array}$ & Negative \\
\hline & & $\begin{array}{l}\text { Total energy } \\
\text { consumption }\end{array}$ & Negative \\
\hline & & $\begin{array}{c}\text { Energy } \\
\text { consumption per } \\
\text { unit of GDP }\end{array}$ & Negative \\
\hline & & $\begin{array}{c}\text { Water } \\
\text { consumption per } \\
\text { unit of GDP }\end{array}$ & Negative \\
\hline & \multirow{5}{*}{ Environment } & $\begin{array}{l}\text { Industrial } \\
\text { wastewater } \\
\text { discharge }\end{array}$ & Negative \\
\hline & & Exhaust emissions & Negative \\
\hline & & $\begin{array}{l}\text { Total amount of } \\
\text { industrial solid } \\
\text { waste generated }\end{array}$ & Negative \\
\hline & & $\begin{array}{l}\text { Comprehensive } \\
\text { utilization of } \\
\text { industrial solid } \\
\text { waste }\end{array}$ & Positive \\
\hline & & $\begin{array}{c}\text { Industrial } \\
\text { pollution control } \\
\text { completed } \\
\text { investment }\end{array}$ & Positive \\
\hline
\end{tabular}




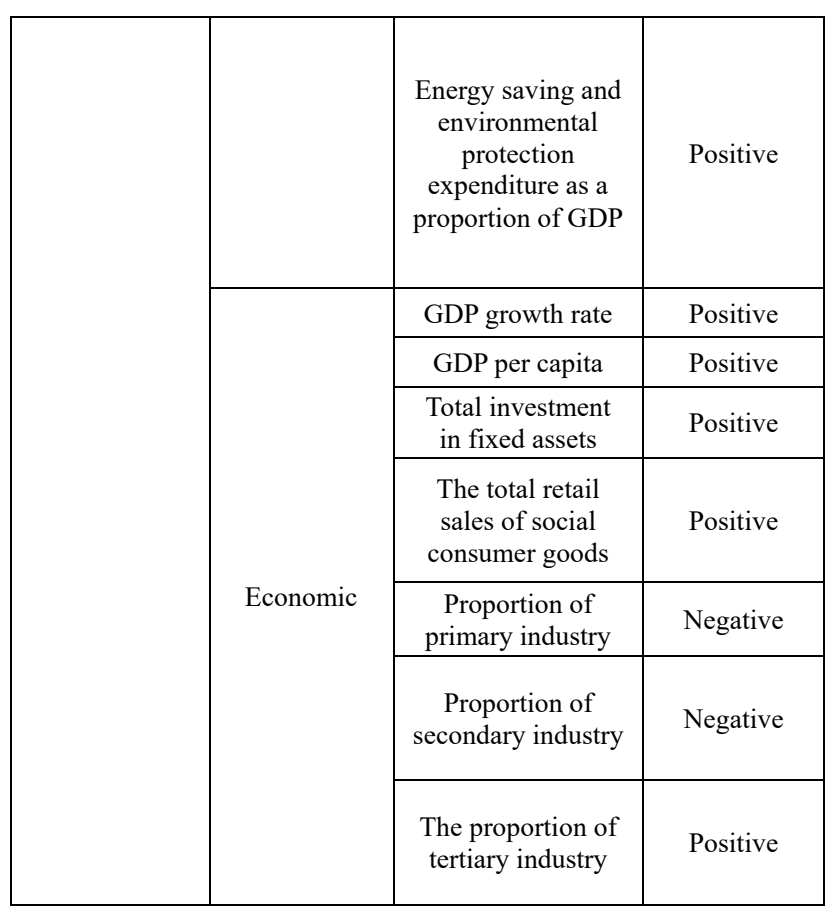

Table 2. Index system of energy consumption level.

\begin{tabular}{|c|c|c|c|}
\hline Target layer & $\begin{array}{l}\text { Criterion } \\
\text { layer }\end{array}$ & Element layer & Indicator \\
\hline \multirow{6}{*}{$\begin{array}{c}\text { Energy } \\
\text { consumption } \\
\text { level }\end{array}$} & \multirow{4}{*}{$\begin{array}{l}\text { energy } \\
\text { structure }\end{array}$} & $\begin{array}{l}\text { Proportion of coal } \\
\text { consumption }\end{array}$ & Positive \\
\hline & & $\begin{array}{l}\text { Proportion of } \\
\text { crude oil } \\
\text { consumption }\end{array}$ & Positive \\
\hline & & $\begin{array}{l}\text { Proportion of } \\
\text { natural gas } \\
\text { consumption }\end{array}$ & Negative \\
\hline & & $\begin{array}{l}\text { Proportion of } \\
\text { electricity } \\
\text { consumption }\end{array}$ & Negative \\
\hline & \multirow{2}{*}{$\begin{array}{l}\text { Energy } \\
\text { consumption }\end{array}$} & $\begin{array}{l}\text { Total energy } \\
\text { consumption }\end{array}$ & Positive \\
\hline & & $\begin{array}{c}\text { Energy } \\
\text { consumption per } \\
\text { unit of GDP }\end{array}$ & Positive \\
\hline
\end{tabular}

\subsection{Elasticity coefficient method}

In this paper, the elastic coefficient method is used to establish the elastic coefficient of energy consumption and high-quality development level. The specific calculation process is detailed in References ${ }^{[12]}$.

According to the increase and decrease changes and numerical comparison between EU and EH, referring to related literature ${ }^{[13]}$, the coupling relationship between energy consumption and high-quality development level is divided into 5 types, as shown in Table 3.

Among the various coupling modes, the developmental coupling relationship with lower energy consumption level and higher high-quality development level is the most ideal model. The growth rate of energy consumption level is slower than the growth rate of highquality development level, second only to the growth coupling model. And the lagging and declining modes of unsatisfactory coordination between energy consumption and high-quality development levels are not conducive to regional coordinated development.

Table 3. Index system of energy consumption level.

\begin{tabular}{|c|c|c|c|c|}
\hline Type & EUR & EHR & $\begin{array}{l}\text { Coefficient } \\
\text { of elasticity }\end{array}$ & Feature \\
\hline Extensive & $\begin{array}{c}\text { EUR } \\
>0\end{array}$ & $\begin{array}{c}\text { EHR } \\
>0\end{array}$ & $\beta>1$ & $\begin{array}{l}\text { The growth rate } \\
\text { of energy } \\
\text { consumption } \\
\text { level is faster } \\
\text { than the growth } \\
\text { rate of high- } \\
\text { quality } \\
\text { development } \\
\text { level }\end{array}$ \\
\hline Growth & $\begin{array}{c}\text { EUR } \\
>0\end{array}$ & $\begin{array}{c}\text { EHR } \\
>0\end{array}$ & $0<\beta<1$ & $\begin{array}{l}\text { The growth rate } \\
\text { of energy } \\
\text { consumption } \\
\text { level is slower } \\
\text { than the growth } \\
\text { rate of high- } \\
\text { quality } \\
\text { development } \\
\text { level }\end{array}$ \\
\hline Declining & $\begin{array}{c}\text { EUR } \\
>0\end{array}$ & $\begin{array}{c}\text { EHR } \\
<0\end{array}$ & $\beta<0$ & $\begin{array}{l}\text { The level of } \\
\text { energy } \\
\text { consumption has } \\
\text { risen, and the } \\
\text { level of high- } \\
\text { quality } \\
\text { development has } \\
\text { fallen }\end{array}$ \\
\hline Developmental & $\begin{array}{c}\text { EUR } \\
<0\end{array}$ & $\begin{array}{c}\text { EHR } \\
>0\end{array}$ & $\beta<0$ & $\begin{array}{c}\text { Reduced energy } \\
\text { consumption and } \\
\text { improved high- } \\
\text { quality } \\
\text { development }\end{array}$ \\
\hline Hysteresis & $\begin{array}{c}\text { EUR } \\
<0\end{array}$ & $\begin{array}{c}\text { EHR } \\
<0\end{array}$ & $\beta<0$ & $\begin{array}{c}\text { Energy } \\
\text { consumption } \\
\text { levels and high- } \\
\text { quality } \\
\text { development } \\
\text { levels have } \\
\text { declined at the } \\
\text { same time }\end{array}$ \\
\hline
\end{tabular}

\section{Research results}

\subsection{Spatiotemporal pattern of high-quality development level and energy consumption level}

\subsubsection{Spatio-temporal pattern of high-quality development level}

From the perspective of the provinces in the Yellow River Basin, the top three provinces in 2004 were Ningxia (0.39), Shandong (0.32), and Shaanxi (0.32); the top three provinces in 2017 were Henan Province (0.77), 
Gansu Province (0.72) and Inner Mongolia Autonomous Region (0.72). Compared with 2004, Henan, Gansu, and Inner Mongolia Autonomous Region have been ranked higher in 2017. Among them, Gansu Province (9 to 2) increased the most, Henan Province (5 to 1 ) increased the least; provinces with the same ranking There are Shanxi and Sichuan provinces; Shandong, Shaanxi, and Qinghai provinces have fallen in the rankings. Among them, Shaanxi Province (2 to 8) has the largest decline, and Shandong Province (3 to 4 ) has the least decline. Henan Province had a slower growth rate from 2004 to 2013 and was once ranked the lowest. After 2013, its growth rate has increased rapidly, reaching the first place. From 2004 to 2016, the overall growth rate of Qinghai Province was relatively average, and from 2016 to 2017 , there was a decline, ranking last.

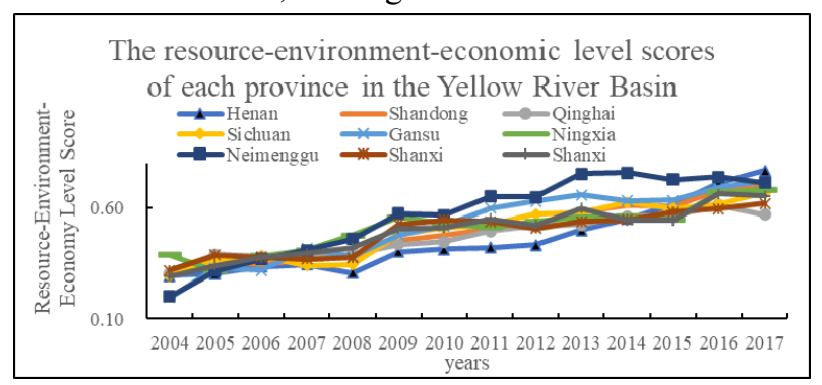

Fig. 1. The resource-environment-economic level scores of each province in the Yellow River Basin.

\subsubsection{Temporal and spatial characteristics of energy consumption level}

From the perspective of the provinces in the Yellow River Basin, the energy consumption levels of the nine provinces (regions) in the Yellow River Basin varied greatly from 2004 to 2009. After 2009, the energy consumption levels of the remaining provinces and regions except Shandong and Qinghai are distributed in space. relatively stable. From the overall trend, the energy consumption level of various provinces is mainly declining, and the economic development level of Qinghai Province is relatively low, so the energy consumption level is relatively low. Shandong Province has a relatively extensive use of energy. From the perspective of energy consumption structure, coal accounts for more than $70 \%$ of the primary energy consumption structure, and oil accounts for more than $20 \%$ of the primary energy consumption structure. It can be seen that the energy structure of Shandong Province has always been dominated by coal resources, the proportion of clean energy is too low, and the problems of high energy consumption and high pollution are serious. As a result, the energy consumption level of Shandong Province remains high, which affects economic development and slows down the improvement of the high-quality development level. After 2012, Shandong's energy consumption level has declined, but it still ranks first. From 2004 to 2017, especially during the implementation of the "Eleventh Five-Year Plan" and "Twelfth Five-Year Plan", various provinces and regions implemented policies for energy conservation, emission reduction and energy structure optimization, and carried out the transformation of the Yellow River Basin development model. The gradual decline in energy consumption per unit of GDP is the main factor in the decline in energy consumption. Among them, the decline in energy consumption in Ningxia Hui Autonomous Region is the most obvious, from 0.48 in 2004 to 0.35 in 2017.

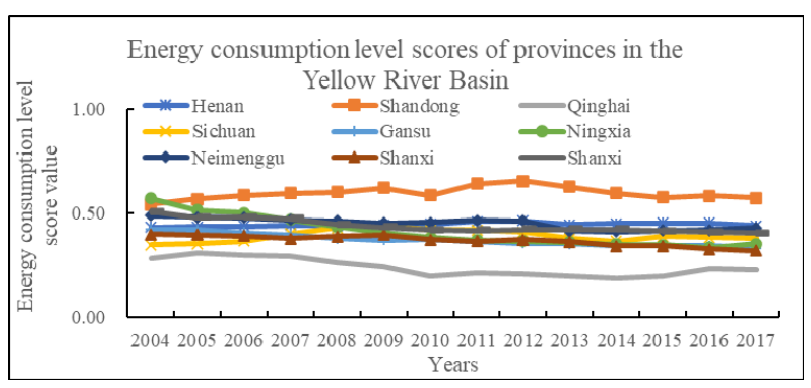

Fig. 2. Energy consumption level scores of provinces in the Yellow River Basin

\subsection{Coupling relationship between energy consumption level and high-quality development level}

Development type, Sichuan, Gansu, and Ningxia are better coupled in the early stage, and Shandong and Shaanxi are better coupled in the middle and late stages. This type means that the level of energy consumption and the level of high-quality development have been better matched. While reducing the level of energy consumption, the level of high-quality development has been improved. The reform of the energy structure and the decline in unit energy consumption have reduced the development's dependence on energy, reduced energy demand, reduced environmental and ecological damage, and promoted the improvement of high-quality development. Many provinces and regions in the upper reaches have a good balance between high-quality development and energy consumption. Shandong Province had a poor coordination relationship between the two in the early stage, and later reforms in energy have improved various indicators and enhanced coordination.

In the growth type, Henan, Shanxi, Inner Mongolia and Qinghai are well coupled in the early stage, and Qinghai and Ningxia are well coupled in the middle and late stages. This type means that energy consumption and high-quality development are slightly less coordinated, and energy consumption and high-quality development have increased simultaneously, but the former is slower than the latter. The increase in energy consumption level represents the increase in energy demand and the need to increase the scale of energy extraction. Economic development is limited by energy consumption, and the dependence on energy is greater. This leads to a decrease in the ecological environment and resource indicators, which in turn affects highquality development hinders the growth of high-quality development levels. However, because its energy consumption promotes the economy more than it 
restrains resources and the environment, the overall level of high-quality development has been improved. This type of coupling is not conducive to the long-term improvement of the level of high-quality development. Therefore, energy reform should be deepened to transform the coupling type into a development type.

Declining type, with Shaanxi in the early stage and Inner Mongolia in the middle and late stages. This type indicates that the level of energy consumption is increasing and the level of high-quality development is declining. It indicates that the growth of energy consumption hinders the improvement of high-quality development and economic development is highly dependent on energy. The unreasonable energy structure and high unit energy consumption are the main reasons for this type. The increase in energy consumption increases the demand for energy, resulting in the destruction of the ecological environment, a substantial reduction in resources, and a decline in the level of highquality development. Inner Mongolia is highly dependent on coal, its energy structure has been unreasonable for a long time, and the growth of energy consumption has improved the economic development level of Inner Mongolia, but it is facing problems such as extensive use of resources and environmental damage. Although Shaanxi Province had poor coordination between energy consumption and high-quality development in the early stage, the energy structure was reformed in the middle and late stages, unit energy consumption was reduced, and the energy consumption level was lowered, and it broke away from recessiontype optimization and became a development-type.

The extensive type is typical of Shandong Province in the early stage. This type represents the simultaneous increase in the level of high-quality development and energy consumption, but energy consumption is higher than the growth rate of high-quality development. Although energy consumption promotes economic growth, making it greater than the negative impact of resources and the environment, energy consumption is the economic development is highly linked, which has caused tremendous pressure on resources and the environment. Shandong Province has coal accounted for more than $70 \%$, the proportion of clean energy is too low, the development and utilization of new energy is insufficient, and most of the generators are coal-fired units, high energy consumption, high pollution, and very low energy use efficiency, which is not conducive to the promotion of high-quality development. Therefore, Shandong Province has carried out drastic reforms in the energy structure in recent years, reducing the proportion of coal, increasing energy utilization, and changing the coupling type to the development type in the middle and late stages.

The lagging type is dominated by Gansu, Ningxia and Shanxi in the mid-term. This type shows that energy consumption and high-quality development are simultaneously declining, and the reduction of energy consumption affects the development of the regional economy. Although energy consumption has decreased, its resilience ability cannot offset the environmental pressure. The advantage of reduced energy consumption does not significantly promote the environment and resources. The regional coordination of energy consumption and high-quality development is not in place, resulting in lagging development. The situation arises. Compared with the mid-term, the provinces in the later period will improve the coordination between energy consumption and high-quality development, and gradually shift to a developmental type.

Although extensive development has brought about an improvement in the economic level, it has also been accompanied by a large amount of energy consumption, which has caused tremendous pressure on resources and the environment, and has hindered the improvement of the level of high-quality development. For the development-oriented provinces and regions, stable growth should be maintained; for the growth-oriented provinces and regions, the coordination of high-quality development and energy consumption should be analysed. Under the circumstance that high-quality development does not slow down, energy consumption should be reduced and gradually transitioned to Development type; while declining provinces and regions shoulder the challenge of improving the level of high-quality development and reducing energy consumption. In addition, with the exception of Qinghai Province, the coupling types of other provinces have undergone significant changes, and the evolution process of coupling relationships between provinces is complicated and different.

\section{Coupling development optimizations}

In the dimension of energy structure, it is necessary to rationalize the structure of energy consumption. First of all, crude oil has a greater weight in energy consumption in the energy structure subsystem. If you want to lower the score of the energy structure subsystem in energy consumption, you should adjust the proportion of crude oil-based energy in the energy consumption structure to reduce the impact. Its dependence will increase the proportion of natural gas and electricity and develop clean energy. Second, the middle and upper reaches of the Yellow River are rich in water resources and should be used rationally to give full play to the hydropower advantages of the middle and upper reaches of the Yellow River. Similarly, Qinghai Province is rich in solar energy and geothermal energy, and Shandong has ocean energy, and both should seize the advantages for development. In terms of other energy sources, renewable energy such as wind energy and biomass energy should also be vigorously developed to increase the proportion of clean energy. Finally, give full play to the power of science and technology, vigorously develop new energy to gradually replace traditional energy, and develop clean and renewable energy.

In terms of energy consumption, reducing total energy consumption and energy consumption per unit of GDP is one of the ways to reduce energy consumption and improve the level of high-quality development in the Yellow River Basin. First, encourage the development of the tertiary industry and high-tech industries. The tertiary 
industry and high-tech industries are low-energyconsuming industries that can effectively control energy consumption without affecting economic development. The provinces and regions of the Yellow River Basin should implement industrial structure reforms, which can not only reduce energy consumption, but also promote the transformation of energy structure. Secondly, energy conservation and emission reduction, reduce energy waste, use innovative technologies to increase coal utilization and reduce coal consumption. In production and life, using energy-saving devices, developing new products for energy saving and emission reduction, making energy consumption fine, clean, efficient can improve energy efficiency and gradually reduce the level of energy consumption. Finally, promote the use of multiple energy sources, such as combined heat and power, to avoid the waste of high-quality energy and low energy utilization in separate power generation or heating, and reduce energy consumption.

In terms of coordinating energy consumption and high-quality development, the provinces and regions of the Yellow River Basin should break through the constraints of administrative boundaries, make the Yellow River Basin as a whole, specify integrated energy consumption and high-quality development goals, and establish a unified mechanism. Divide different functional areas, give full play to the advantages of various provinces and regions, and improve the efficient allocation of various elements.

\section{Conclusion}

The level of high-quality development in the Yellow River Basin is generally increasing, and the level of energy consumption is generally decreasing. The coupling between energy consumption and high-quality development has been optimized year by year. The Yellow River Basin has a coupled relationship between energy consumption and high-quality development. The first stage is mainly growth-oriented, and the latter stage is mainly development-oriented, and the overall trend is in development. With the exception of Qinghai Province, the coupling types of other provinces have undergone significant changes, and the evolution process of coupling relationships between provinces is complicated and different.

\section{References}

1.Xi J. (2019) Speech at the Symposium on Ecological Protection and High-quality Development of the Yellow River Basin. J. Seeking Truth., 20: 4-11.

2.Jin B. (2018) Economic Research on "High-quality Development". J. China Industrial Economy., 4:5-18.

3.Wan G., Lv J. (2021) China's high-quality development: the construction and measurement of an index system based on people's well-being. J. Jiangsu Social Sciences., 1:52-61.
4.Kraft J., Kraft A., (1978) On the Relationship Between Energy and GNP. J. Energy Development., 2: 401403.

5.Soytas, U., Ramazan S. (2003) Energy Consumption and GDP: Causality Relationship in G-7 Countries and Emerging Markets. J. Energy Economics, 1: 3337.

6.Zhao J., Fan Jitao. (2007) An Empirical Study on the Internal Compliance between Economic Growth and Energy Consumption. J. Economic Research., 8: 3142.

7.Zhang Z. (2018) An empirical analysis of the relationship between my country's economic growth and energy consumption. J. Business Economics Research., 17: 36-39.

8.Xu Y. (2017) An Empirical Study on the Relationship between New Energy Consumption and my country's Economic Growth. J. Economic Aspects., 5:69-74.

9.He J., Fu C., Long Y. (2021) Theoretical analysis and implementation path of the energy revolution promoting the rise of the central region. J. Chinese Engineering Science., 1: 60-67.

10.Zhang X. (2020) Energy transition promotes the highquality development of my country's economy. J. New West., 12: 7-7.

11.Zhang C., Li Z., Dong X. (2014) Analysis of the level of agricultural development in the BRICS countries: a comparative study based on the entropy method and the coefficient of variation method. J. Science and Technology and Economy., 162: 42-46.

12.Cui P., Zhao Y., Xia S., Yan J. (2020) Ecological environment and high-quality development measurement and time-space coupling characteristics of the Yellow River Basin. J. Economic Geography., 5: 50-57.

13.Sridharan S., Tunstall H., Lawder R. (2007) An exploratory spatial data analysis approach to understanding the relationship between deprivation and mortality in Scotland. J. Social Science \& Medicine., 9: 1942 -1952. 